\title{
Actinic keratosis associated with squamous and basal cell carcinomas: an evaluation of neoplastic progression by a standardized AgNOR analysis
}

\author{
G. Giuffrè,, ${ }^{1}$ V. Barresi, ${ }^{1}$ A. Catalano, ${ }^{2}$ A. Cappiello, ${ }^{2}$ F. Stagno d'Alcontres, ${ }^{2}$ G. Tuccari $^{1}$ \\ ${ }^{1}$ Department of Human Pathology, Polyclinic Pad. D; ${ }^{2}$ Department of Surgical Specialties, University of \\ Messina, Italy
}

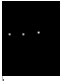

(C)2008 European Journal of Histochemistry

In an attempt to investigate the neoplastic progression in different stages of actinic keratosis (AK), a standardized AgNOR analysis was performed in 94 cases of AK, 35 of which were associated with squamous cell carcinoma (SCC) or basal cell carcinoma (BCC), and in 31 cases of SCC and 22 cases of BCC. The cases were subdivided into low- and highAgNOR-expressing (AgNOR status) AK by using the mean area of AgNORs per cell (NORA) value $\left(3.996 \mu \mathrm{m}^{2}\right)$ as the cut-off. In AK samples, a progressive increase of the mean NORA value from Stage I to Stage IV was encountered. In addition, a significantly higher mean NORA value was found in the AK cases associated with SCC, in comparison to those without SCC; by contrast, no significant differences in the mean NORA value were noted between AK cases with or without BCC. A highly significant association between a high AgNOR quantity and the coexistence of SCC was encountered in AK; no association was appreciable between the AgNOR quantity and the co-occurrence of BCC. Moreover, when the co-existence of SCC in AK was considered as the reference point, the AK cases associated with SCC mostly (95.5\%) presented a high AgNOR quantity (high sensitivity), but only $57.6 \%$ of cases without SCC displayed a low AgNOR quantity (low specificity). Additionally, our data document that the standardised AgNOR analysis represents a strong negative predictor for the association between SCC and AK. Indeed, a low AgNOR quantity mostly is associated with AK cases without SCC.

Key words: Actinic keratosis, squamous cell carcinoma, AgNORs, standardized AgNOR analysis, proliferation.

Correspondence: Giovanni Tuccari,

Department of Human Pathology

A.O.U. Policlinico G. Martino - Pad. D

98125 Messina, Italy

Tel.: +39.090.2212539.

fax: +39.090 .2938324 .

E-mail: tuccari@unime.it

Paper accepted on February 12, 2008

European Journal of Histochemistry

2008; vol. 52 issue 1 (Jan-Mar): 53-60
T $\mathrm{t}$ is well known that actinic keratosis $(A K)$ is a common, potentially serious skin condition which is considered to be the earliest stage in the development of skin cancer; moreover, the great majority of AK can be graded in different histological stages on the grounds of basal layer atypia and extension of dysplasia into epidermis. Although the rate of malignant transformation into squamous cell carcinoma (SCC) is estimated to be about 10\% (Onodera et al. 1996; Goldberg et al. 2000; Cassarino et al. 2006), AK may be hardly distinguished with certainty from invasive squamous cell carcinoma in some cases, especially in superficial or tangentially-embedded biopsies (Davis et al. 2005); in fact, AK has been considered to be a very superficial, keratotic type, squamous cell carcinoma by many Authors (Cockerell et al. 2000; Goldberg et al. 2000; Heaphy et al. 2000; Lober et al. 2004). However, it has been noted that some cases of AK may become resistant to standard therapies and they should be unequivocally considered as a new subtype of $A K$, exhibiting proliferative histologic characteristics and occurring with concomitant associated basal cell carcinoma (BCC) or SCC of the skin (Goldberg et al. 2000; Tuccari et al. 2001; Cassarino et al. 2006).

The AgNOR technique, a very simple and inexpensive silver-staining procedure, allows to visualize at the light microscopic level a set of argyrophilic nonhistone proteins localized in the nucleolar organizer region (Derenzini et al. 1991; Ploton et al. 1996). These silver-stained nucleolar organizer region (AgNOR) proteins are associated with ribosomal genes, and their quantity has been demonstrated to be strictly related to the rapidity of cell proliferation (Derenzini et al. 1989; Derenzini et al. 1990; Öfner et al. 1992). Furthermore, studies concerning this histochemical method have shown the prognostic value of AgNOR quantity as an independent variable, able to predict the recurrences and/or the overall survival in various kinds of malignancies as well 
as of skin tumors (Egan et al. 1988; Rüschoff et al. 1990; Delahunt et al. 1991; Eusebi et al. 1991; De Rosa et al. 1992; Pich et al. 1992; Aubele et al. 1994; Pich et al. 1994; Öfner et al. 1995b; Antonangelo et al. 1997; Giuffrè et al. 1998; Tuccari et al. 1999; Giuffrè et al. 2001; Giuffrè et al. 2006). Moreover, in a previous study (Tuccari et al. 2001), we applied for the first time the standardized procedure proposed by the European Committee on AgNOR Quantification (Öfner et al. 1995b) to determine the AgNOR quantity in the different stages of actinic keratosis, thus identifying those cases with proliferative characteristics and a strong propensity to develop infiltrative SCC (Tuccari et al. 2001); we concluded that in AK a progressively increased cell cycle speed proceeded in the meantime the epithelial dysplasia appears and it is extended to the different layers of the epidermis (Tuccari et al. 2001). Moreover, the highest mean AgNOR quantity encountered in AK Stage IV was very similar to that found in SCC, suggesting a similar proliferation rate in these two skin lesions (Tuccari et al. 2001). We analysed herein the AgNOR quantity in cases with co-existing AK and SCC or BCC in comparison to data coming from $A K$ alone in order to assess the predictive value of AgNOR method in the identification of aggressive and evolutive AK.

\section{Materials and Methods}

One hundred-forty seven sun-exposed skin surgical samples were collected from files of our Institution, including 94 cases of AK (53 male, 41 female; mean age 67.9 years, ranging from 37 to 88 years), 35 of which were associated with coexisting SCC (22) or BCC (Giuffrè et al. 1998). All cases were graded according to criteria of Hashimoto and Mehregan (Hashimoto et al. 1990) in four histological stages: 23 Stage I (Basal layer atypia), 28 Stage II (Lower epidermal dysplasia), 23 Stage III (Middle epidermal dysplasia) and 20 Stage IV (Total epidermal dysplasia). Moreover, 31 cases of SCC (14 male, 17 female; mean age 71.4 years, ranging from 58 to 93 years), 22 of which were AK-associated, and 22 cases of BCC (17 male, 5 female; mean age 67.5 years, ranging from 53 to 83 years), 13 of which were AK-associated, were also analyzed. Finally, 10 normal skin fragments were taken during laparotomic surgery and utilized as tissue control. The assessment of diagnosis and staging was obtained by 2 pathologists with a good correlation and reproducibility; in the cases evaluated in different manner, consensus was reached after discussion using a double-headed microscope.

All surgical samples had been fixed in $10 \%$ neutral formalin for 12-24 hrs at room temperature and then embedded in paraffin at $56^{\circ} \mathrm{C}$. From each tissue block, two consecutive $4 \mu \mathrm{m}$ thick sections were cut and mounted on silane-coated glasses, then dewaxed in xylene, rehydrated in graded ethanols and submitted to haematoxylin and eosin ( $H \& E$ ) stain and to the AgNOR technique according to guidelines of the Committee on AgNOR Quantification (Öfner et al., 1995a), respectively. In detail, sections were immersed in sodium citrate buffer ( $\mathrm{pH} \mathrm{6)}$ and incubated in wet autoclave at $120^{\circ} \mathrm{C}$ (1.1-1.2 bar, at sea level) for $20 \mathrm{~min}$ and then allowed to cool down to $37^{\circ} \mathrm{C}$. Subsequently, slides were immersed in a freshly prepared silverstaining solution containing one part of volume of $2 \%$ gelatin in $1 \%$ formic acid and two parts of $25 \%$ aqueous silver nitrate solution, at $37^{\circ} \mathrm{C}$ in a thermostatically controlled environment for 11 $\min$. The reaction was then stopped by washing the slides with bidistilled-deionized water in order to remove unwanted silver precipitates. Finally, all sections were dehydrated in ascending ethanols, clarified in xylene and mounted with a synthetic medium (Permount, Fisher Scientific, Hampton, New Hampshire, USA).

The quantification of AgNORs was performed by an image analysis system consisting of an optical microscope (DM RB, Leica Microsystems) fitted with a single chip color CCD video camera (Ikegami ICD-840PDC, Ikegami Tsushinki Co. Ltd., Tokyo, Japan) having a resolution of $460 x$ 420 (horizontal $x$ vertical) TV lines and an image processing unit installed in a computer. For each slide examined, microscopic fields representative of the lesions were assessed excluding areas in which regressive changes as well as technical artifacts were present, as compared with the corresponding $H \& E$ stained section. The mean area $\left(\mu \mathrm{m}^{2}\right)$ of AgNORs per cell (NORA) was evaluated using cells in one focal plane with a $\times 40$ objective lens in at least 100 nuclei per specimens (mean 130); specific softwares, IM 5200 (Microscience Inc., Phoenix Technology Inc., Seattle, Washington, USA) and AgNOR (Immagini e Computer, Rho-Milan, Italy), 
were utilized to determine mean NORA values per cell and per case, respectively.

After testing the normal distribution of NORA values in all groups of patients by KolmogorovSmirnov test, parametric tests were applied. A statistical descriptive analysis (mean value and standard deviation) was performed for each case of different groups of cutaneous lesions, while differences among categories were assessed by analysis of variance and the Newman-Keuls' multiple comparisons test. Moreover, the AK cases were dichotomously divided into low- and high-AgNOR-expressing (AgNOR status) by using the mean NORA value encountered in AK as the cut-off point. Finally in $A K$, differences between AgNOR status and co-existence or not with cutaneous neoplasms (SCC or BCC) were assessed by Fisher's exact test. Sensitivity, specificity, negative predictive value, positive predictive value of AgNOR status were also evaluated taking as reference point the co-existence of SCC or BCC. A probability $(p)$ value less than 0.05 was considered statistically significant. Data were analyzed using the SPSS package version 6.1.3 (SPSS Inc., Chicago, IL, USA).

\section{Results}

An adequate silver-staining intensity, homogeneously present throughout the whole section, was appreciable in all the AK, as well as in the neoplastic and control cutaneous fragments by AgNOR method. Mature lymphocytes, whenever present, exhibited a single round-shaped, centrally localized AgNOR.

In AK lesions, the AgNORs were clearly distinguishable as black dots in the nuclei of the epidermal basal layer as well as within the nucleoli (Figure $1 \mathrm{a}, \mathrm{b}$ ); moreover, irregularly shaped aggregates of AgNORs were present in disarrayed large hyperchromatic pleomorphic as well as in dyskeratotic cells, which occupied half the thickness of the epidermis and may reach the granular layer. In AK samples, the mean NORA value was $3.996 \mu \mathrm{m}^{2}$ (SD \pm 1.014 ) with a progressive increase in the mean NORA value (Figure $1 \mathrm{a}, \mathrm{b}$ ) moving from Stage I to Stage IV (Table 1). Highly significant differences $(p<0.001)$ were noted when Stages I or II were compared with Stages III or IV, respectively; in addition, a significantly higher mean NORA value $(p<0.001)$ was obtained in the Stage III cases in

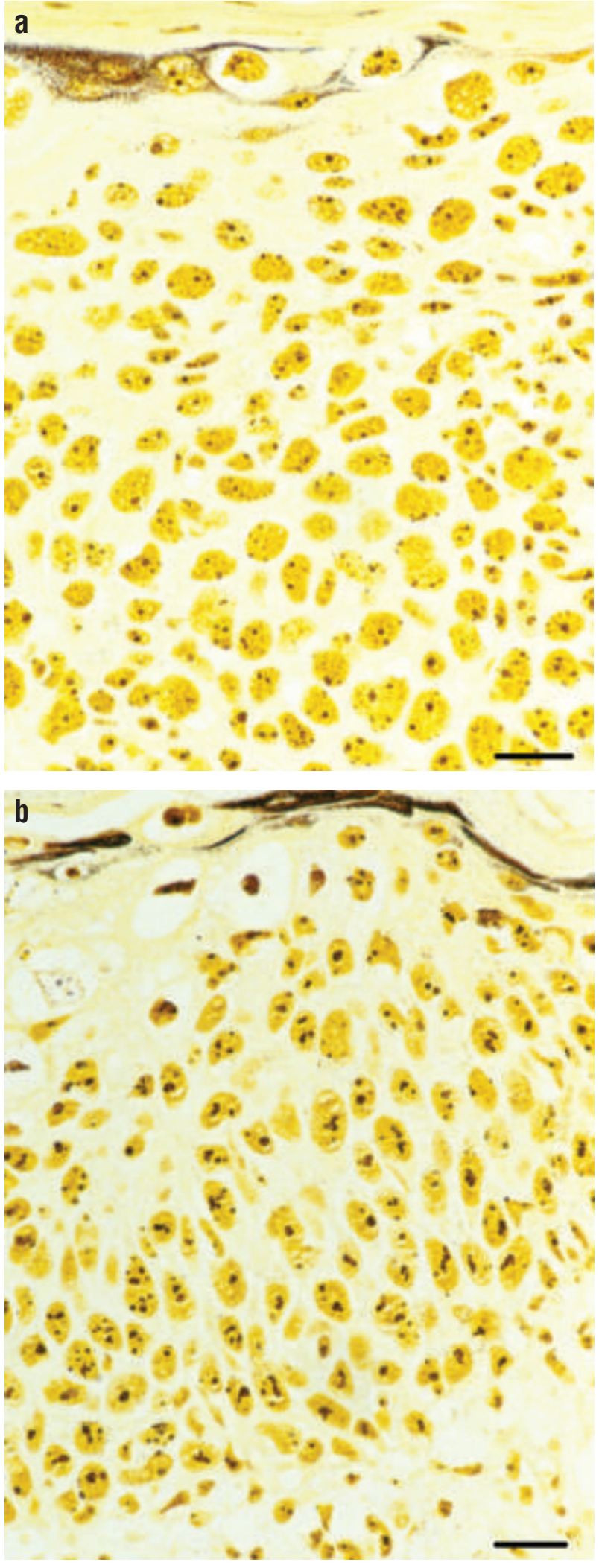

Figure 1. A moderate amount of intranuclear silver precipitates in a case of AK considered as low-AgNOR-expressing (a); a larger and diffuse quantity of intranuclear black dots in a high-AgNORexpressing AK case (b) (Standardized AgNOR method, scale bar represents $20 \mu \mathrm{m}$ ). 
comparison to those with a Stage IV. By contrast, no significant difference was found between Stages II and I of AK cases.

In 59 AK cases without any evidence of SCC or $\mathrm{BCC}$, the mean NORA value was $3.786 \mu \mathrm{m}^{2}$ (SD $\pm 0.955)$. Conversely, 22 cases of $A K$ associated with SCC showed a mean NORA value of 4.969 $\mu \mathrm{m}^{2}(\mathrm{SD} \pm 0.507)$, while a lower mean NORA value was encountered in $13 \mathrm{AK}$ co-existing with $\mathrm{BCC}$ (3.303 $\left.\mu \mathrm{m}^{2} ; \mathrm{SD} \pm 0.796\right)$. A highly significant difference $(p<0.001)$ was found in the comparison of AK cases with or without co-existence of SCC; no differences were noted between AK cases with or without the presence of BCC.

In SCC, the neoplastic elements showed an evident increase of AgNORs in the nucleus, mostly organized in irregularly shaped aggregates (Figure 2 ); the number and distribution of the intranuclear black dots were strikingly different from that of normal skin. The mean NORA value was $5.374 \mu \mathrm{m}^{2}$ ( $S D \pm 0.666)$ and it was very similar to that encountered in AK Stage IV $\left(5.247 \mu \mathrm{m}^{2}\right.$; SD \pm 0.554$)$. In detail, cases of pure SCC showed a mean NORA value of $5.193 \mu^{2}(S D \pm 0.924)$, while SCC associated to AK cases exhibited a mean NORA value of $5.448 \mu \mathrm{m}^{2}(\mathrm{SD} \pm 0.536)$. No statistical differences between these two latter groups of SCC were noted.

In BCC, the AgNORs were mainly localized in the basal elements with a scattered pattern (Figure 3); the corresponding NORA value was $3.092 \mu \mathrm{m}^{2}$ (SD $\pm 0.323)$. In detail, cases of pure BCC showed a mean NORA value of $3.050 \mu \mathrm{m}^{2}(S D \pm 0.251)$, while BCC associated to AK cases exhibited a mean NORA value of $3.126 \mu \mathrm{m}^{2}(S D \pm 0.380)$. No statistical differences between these two latter groups of BCC were noted.

In the control normal skin specimens, the lowest

Table 1. Mean NORA values $\left(\mu \mathrm{m}^{2}\right) \pm \mathrm{SD}$ obtained from skin samples of Actinic Keratosis (AK), Squamous Cell Carcinoma (SCC), Basal Cell Carcinoma (BCC) and Normal skin (N).

\begin{tabular}{|c|c|c|c|c|}
\hline & No. & NORA & $S D$ & Significance \\
\hline Actinic keratosis & 94 & 3.996 & \pm 1.014 & $p<0.001$ (AK vs. SCC, BCC, N) \\
\hline Stage I & 23 & 3.193 & \pm 0.762 & $\begin{array}{c}p<0.001 \text { (I vs. III, IV) } \\
p>0.05 \text { (I vs. II) }\end{array}$ \\
\hline Stage II & 28 & 3.421 & $\pm 0,752$ & $p<0.001$ (II vs. III, IV) \\
\hline Stage III & 23 & 4.413 & \pm 0.322 & $p<0.001$ (III vs. IV) \\
\hline Stage IV & 20 & 5.247 & \pm 0.554 & \\
\hline Squamous cell carcinoma & 31 & 5.374 & \pm 0.666 & $p<0.001$ (SCC vs. BCC, N) \\
\hline Basal cell carcinoma & 22 & 3.092 & \pm 0.323 & $p<0.001$ (BCC vs. N) \\
\hline Normal skin & 10 & 1.869 & \pm 0.332 & \\
\hline
\end{tabular}

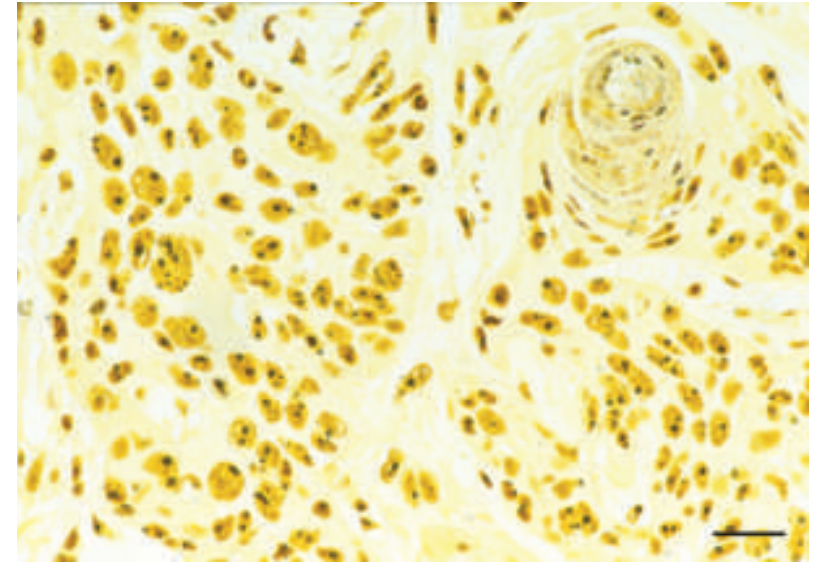

Figure 2. Squamous neoplastic cells exhibited an evident increase of AgNORs in the nucleus, mostly organized in irregularly shaped aggregates (Standardized AgNOR method, scale bar represents $20 \mu \mathrm{m}$ ).

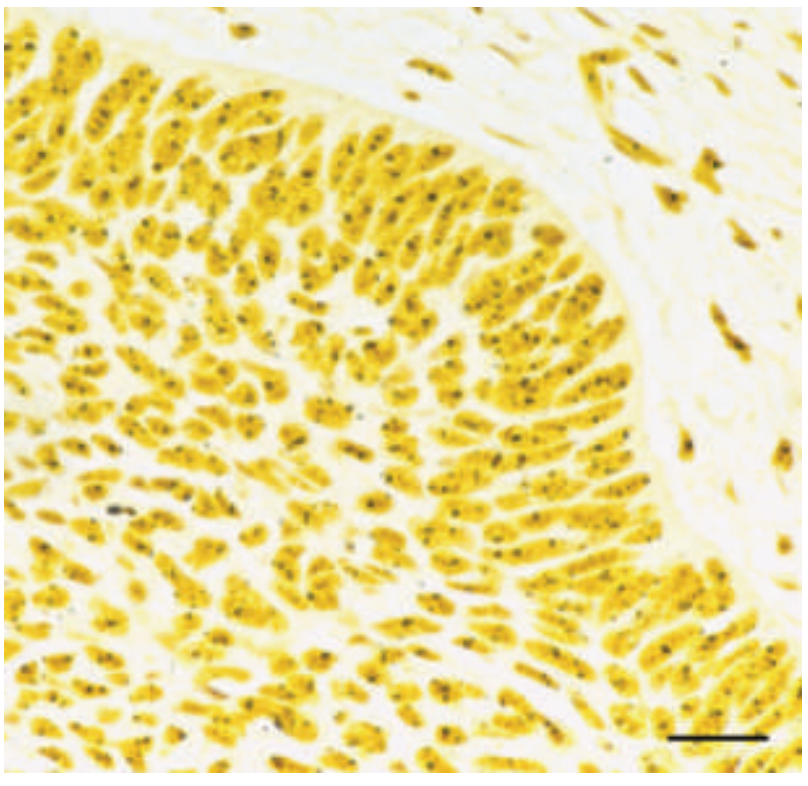

Figure 3. The AgNORs were mainly localized in the basal elements of BCC with a scattered pattern (Standardized AgNOR method, scale bar represents $20 \mu \mathrm{m}$ ).

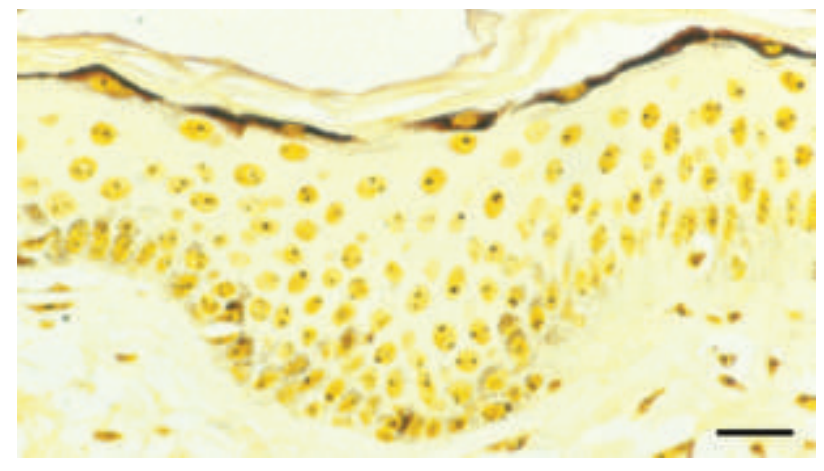

Figure 4. Single AgNOR dots were present in the epidermal elements of normal skin (Standardized AgNOR method, scale bar represents $20 \mu \mathrm{m}$ ). 
mean NORA value was found (1.869 $\mu^{2}$; SD \pm 0.332 ) (Figure 4).

When all specimens were subdivided into four groups, namely normal skin, BCC, AK and SCC, a highly significant difference in the mean NORA value $(p<0.001)$ was found among them, although some degree of overlap among single mean NORA values was encountered.

Regarding the AgNOR status, AK cases were subdivided into 35 low- and 46 high-AgNOR-expressing (Figure $1 \mathrm{a}, \mathrm{b}$ ), taking into consideration the value of $3.996 \mu \mathrm{m}^{2}$ as the cut-off point. A highly significant association between AgNOR status and coexistence of SCC $(p<0.00001)$ was encountered in AK (Table 2); no association was appreciable between AgNOR status and co-existence of BCC. Moreover when the AK cases were stratified by stage, among 40 AK cases of I-II stage, 32 cases without any association with SCC were lowAgNOR-expressing but 8 cases were high-AgNORexpressing, 7 of which were SCC-associated $(p<0.00001)$. By contrast, in AK cases of III-IV stage, 38/41 were high-AgNOR-expressing and 14/41 were SCC-associated; only 3 cases were lowAgNOR-expressing, 2 of which were not SCC-associated ( $p=0.70122$ ).

Finally, taking as a reference point the co-existence of SCC in AK, the probability that AK cases associated with SCC display a high AgNOR quantity (sensibility) was $95.5 \%$ (21/22 AK with SCC displayed a high AgNOR quantity), whereas the probability that a case without SCC was characterized by a low AgNOR quantity (specificity) was $57.6 \%$ (a low AgNOR quantity was detetected in $34 / 59$ cases of AK without SCC). The probability that a highly AgNOR expressing AK was associated with SCC (positive predictive value) was $45.7 \%$ (21/46 highly AgNOR expressing AK cases were associated with $\mathrm{SCC}$ ), while the probability that a low AgNOR expression identified a case of AK without SCC (negative predictive value) was, 97.1\% (34/35 cases with a low AgNOR quantity were not associated with SCC).

\section{Discussion}

In order to differentiate AK from malignant epithelial cutaneous tumors, only few studies using the AgNOR method, exclusively based on a subjective counting procedure of intranuclear silver dots,
Table 2. Relationship between AgNOR status and coexistence of squamous cell carcinoma (SCC) in actinic keratosis $(p<0.00001)$.

\begin{tabular}{lccc}
\hline & \multicolumn{3}{c}{ AgNOR status } \\
\cline { 2 - 3 } & Low AgNOR quantity & High AgNOR quantity & Total \\
\hline Actinic keratosis & 34 & & \\
Without SCC & 1 & 25 & 59 \\
Association with SCC & 35 & 46 & 22 \\
Total & & & 81 \\
\hline
\end{tabular}

have been carried out (Egan et al. 1988; Heinisch et al. 1994; Onodera et al. 1996; Khanna et al. 2001; Romão-Corrèa et al. 2005); in some reports, the AgNOR numbers in AK were significantly lower than those observed in SCC as well as in BCC (Egan et al. 1988; Onodera et al. 1996). Nevertheless, a comparative AgNOR analysis among different $A K$ stages has been already investigated by our group by using the standardized AgNOR method (Tuccari et al. 2001). This previous study was the first in which the standardized AgNOR analysis had been performed in cutaneous preneoplastic and neoplastic pathology according to the guidelines of the Committee on AgNOR Quantification (Öfner et al. 1995a). In particular, by wet-autoclave pre-treatment, we obtained a constantly high staining quality of single-interphase AgNORs, irrespective of the duration of formalin fixation and archival storage, similarly to that elsewhere reported (Öfner et al. 1996). Moreover, the quantification of AgNOR area was made by an image analyzer system, being more objective, free of observer bias and less time consuming than counting AgNORs by eye (Rüschoff et al. 1990b; Öfner et al. 1996). Therefore, the evaluation of changes in the number and shape of nucleoli present in malignant cells from human skin cancers, performed by not standardized recommended procedures (Romão-Corrèa et al. 2005), should be considered with caution; in fact, if the AgNOR evaluation in skin tumours is approached by subjective counts of single or aggregate specific silver precipitates, either intranuclear or intranucleolar, conflicting data about BCC and SCC have been reported (Egan et al. 1988; Khanna et al. 2001).

In the present series, utilizing the above mentioned standardized procedure, we have found a highly significant difference of the AgNOR quantity among $A K, B C C$ and SCC, examined as pure enti- 
ties, thus suggesting a progressive increase of the proliferation rate moving from preneoplastic lesions to malignant neoplasias. Moreover, in AK cases, the AgNOR analysis showed a progressive increase of the mean NORA values moving from Stage I to Stage IV, with a highly significant difference among low stages and Stage III or IV; by contrast, no difference was evident between Stage I and II. Furthermore, when we compared AK cases with or without co-existence of SCC, a highly significant difference $(p<0.001)$ emerged while no differences were appreciable between $A K$ cases with or without the presence of BCC. On the other hand, pure SCC cases exhibited a quantity of AgNORs quite similar to that encountered in AK cases of Stage IV, whereas lower mean NORA values were found in pure BCC. No significant differences were achieved when a comparison was made between pure SCC or AK-associated SCC as well as between pure BCC or AK-associated BCC. Of course, the lowest mean NORA value was present in the control normal skin specimens. Finally, considering the mean NORA value of AK cases as a cut-off point in order to define low- and high-AgNOR-expressing cases, a highly significant association between AgNOR status and coexistence of SCC $(p<$ 0.00001 ) was encountered; by contrast, no association was appreciable between AgNOR status and co-existence of BCC. However, taking as reference point the co-existence of SCC in AK, the sensitivity of AgNOR status was very high $(95.5 \%)$, with a down-specificity; additionally, our data document the standardised AgNOR analysis represents a strong negative predictor (negative predictive value $=97.1 \%$ ) for the association between SCC and AK. Moreover, this aspect appears greatly evident when only low stage AK cases were considered; in fact, all cases displaying a low AgNOR quantity showed no association with SCC, while 7/8 charcterized by a high AgNOR quantity were SCC-associated. In biological terms, it is well established the AgNOR quantity allows to obtain information on the rate of ribosome biogenesis in pathological tissue specimens (Derenzini et al., 2000); in fact, the AgNOR distribution is strictly related to the RNA polymerase I activity, so an higher AgNOR value corresponds to a greater rRNA transcription (Derenzini et al., 2000). However, an up-regulation of ribosome biogenesis enhancing the cellular proliferation rate has been reported in breast cancer, in association with an altered status in pRB and p53 (Trerè et al., 2004); therefore, the nucleolar hypertrophy and the high ribosome biogenesis may represent the final effects of the loss of the inhibitory effects on pRB and p53 on RNA polymerase I activity (Trerè et al., 2004). On the light of these considerations, in AK a significantly increased AgNOR quantity may characterize those cases with deleted $\mathrm{pRB}$ and mutated p53, identifying patients with deregulated cell cycle and able to easily progress towards SCC.

Therefore, these latter findings further improve our understanding of pathobiological changes accompanying the progression of AK into SCC. On the basis of our observations, the determination of AgNOR quantity may represent an useful additional tool to identify patients, mainly with low stage of AK, able to develop a co-existent SCC. However, from a practical point of view in dermatopathology, the AgNOR may be utilized as an objective and inexpensive method in the assessment of the rank of risk in $A K$, mainly when skin lesions are incompletely removed by small biopsies or partial excisions.

\section{References}

Antonangelo L, Bernardi F, Capelozzi VL, Takagaki TY, Younes RN, Yagi $N$, et al. Morphometric evaluation of argyrophilic nucleolar organizer region is useful in predicting long-term survival in squamous cell carcinoma of the lung. Chest 1997;111:110-4.

Aubele M, Auer G, Jutting U, Falkmer U, Gais P. Prognostic value of quantitatively measured AgNORs in ductal mammary carcinoma. Analyt Quant Cytol Histol 1994;16:211-8.

Cassarino DS, De Rienzo DP, Barr RJ. Perspectives in dermatopathology. J Cutan Pathol 2006;33:191-206.

Cockerell CJ. Histopathology of incipient intradermal squamous cell carcinoma ("actinic keratosis"). J Am Acad Dermatol 2000;42: 11-7.

Davis DA, Donahue JP, Bost JE, Horn TD. The diagnostic concordance of actinic keratosis and squamous cell carcinoma. J Cutan Pathol 2005;32:546-51.

Delahunt B, Ribas JL, Nacey JN, Bethwaite PB. Nucleolar organizer regions and prognosis in renal cell carcinoma. J Pathol 1991;163:31-7.

Derenzini M, Pession A, Farabegoli F, Trerè D, Badiali M, Dehan P. Relationship between interphasic nucleolar organizer regions and growth rate in two neuroblastoma cell lines. Am J Pathol 1989; 134:925-32.

Derenzini M, Pession A, Trerè D. Quantity of nucleolar silver-stained proteins is related to proliferating activity in cancer cells. Lab Invest 1990;63:137-40.

Derenzini M, Ploton D. Interphase nucleolar organizer regions in cancer cells. Int Rev Exp Pathol 1991;32:149-92.

Derenzini M, Trerè D, Pession A, Govoni M, Sirri V, Chieco P. Nucleolar size indicates the rapidity of cell proliferation in cancer tissues. $J$ Pathol 2000;191:181-6.

De Rosa G, Staibano S, Barra E, Zeppa P, Salvatore G, Vetrani A, et al. Nucleolar organizer regions in aggressive and nonaggressive basal cell carcinoma of the skin. Cancer 1992;69:123-6.

Egan MJ, Crocker J. Nucleolar organizer regions in cutaneous tumours. J Pathol 1988;154:247-53.

Eusebi V, Cattani MG, Lamovec J, Trerè D, Ceccarelli C, Veronesi C, et 
al. Prognostic relevance of silver stained nucleolar proteins in sarcomatoid carcinomas of the breast. Ultrastruct Pathol 1991; 15:203-14.

Giuffrè G, Caruso RA, Barresi G, Tuccari G. Prognostic significance of standardized AgNOR analysis in early and advanced gastric carcinomas. Virchows Arch 1998;433:261-6.

Giuffrè G, Fulcheri E, Gualco M, Fedele F, Tuccari G. Standardized AgNOR analysis as a prognostic parameter in endometrial carcinoma, endometrioid type. Analyt Quant Cytol Histol 2001;23:31-9.

Giuffrè G, Mormandi F, Barresi V, Bordi C, Tuccari G, Barresi G. Quantity of AgNORs in gastric endocrine carcinoid tumours as a potential prognostic tool. Eur J Histochem 2006;50:45-50.

Goldberg LH, Chang JR, Baer SC, Schmidt JD. Proliferative actinic keratosis:three representative cases. Dermatol Surg 2000;26:65-9.

Hashimoto K, Mehregan AH. Actinic keratosis. In Hashimoto K, Mehregan $\mathrm{AH}$, eds. Tumors of epidermis. Butterworths, Boston, 1990, pp. 168-201.

Heaphy MR, Ackerman B. The nature of solar keratosis: a critical review in historical perspective. J Am Acad Dermatol 2000;43:13850.

Heinisch G, Barth J. Use of the AgNOR method for the differential diagnosis of tumors and for the quantification of non-neoplastic epidermal hyperproliferation in dermatohistology. Zentralbl Pathol 1994; 140:95-101.

Khanna AK, Giri AK, Khanna A, Kumar M. Nucleolar organizer region count and subjective AgNOR pattern assessment (SAPA) score in skin tumors. J Surg Oncol 2001;78:273-8.

Lober BA, Fenske NA. Optimum treatment strategies for actinic keratosis (intraepidermal squamous cell carcinoma). Am J Clin Dermatol 2004;5:395-401.

Öfner D, Hittmair A, Marth C, Öfner C, Tötsch M, Daxenbichler G. Relationship between quantity of silver stained nucleolar organizer region associated proteins (AgNORs) and population doubling time in ten breast cancer cell lines. Path. Res. Pract. 1992;188:742-6.

Öfner D, Aubele M, Biesterfeld S, Derenzini M, Gimenez-Mas JA,Hufnagl $P$, et al. Guidelines of AgNOR quantification - first update. In: Hofstadter $F$, Knuchel $R$, Rüschoff J. Cell proliferation assessment in oncology. Virchows Arch 1995a;427:341.

Öfner D, Riedmann B, Maier H, Hittmair A, Rumer A, Totsch M, et al. Standardized staining and analysis of argyrophilic nucleolar organ- izer region associated proteins (AgNORs) in radically resected colorectal adenocarcinoma - Correlation with tumour stage and longterm survival. J Pathol 1995b;175:441-8.

Öfner D, Schmid KW. Standardized AgNOR analysis: its usefulness in surgical oncology. Histochem Cell Biol 1996;106:193-6.

Onodera H, Nakamura S, Sugai T. Cell proliferation and p53 protein expression in cutaneous epithelial neoplasms. Am J Dermatopathol 1996;18:580-8.

Pich A, Chiusa L, Pisani P, Krengli M, Pia F, Navone R. Argyrophilic nucleolar organizer region counts and proliferating cell nuclear antigen scores are two reliable indicators of survival in pharyngeal carcinoma. J Cancer Res Clin Oncol 1992;119:106-10.

Pich A, Chiarle R, Chiusa L, Palestro G. Argyrophilic nucleolar organizer region counts predict survival in thymoma. Cancer 1994; 74:1568-74.

Ploton D, Menager M, Jeannesson P, Himber G, Pigeon F, Adnet JJ. Improvement in the staining and in the visualization of the argyrophilic proteins of the nucleolar organizer region at the optical level. Histochem J 1986;18:5-14.

Romão-Corrêa RF, Maria DA, Soma M, Sotto MN, Sanches JA Jr, Neto $C F$, et al. Nucleolar organizer region staining patterns in paraffin-embedded tissue cells from human skin cancers. J Cutan Pathol 2005;32:323-8.

Rüschoff J, Bittinger A, Neumann K, Schmitz-Moormann P. Prognostic significance of nucleolar organizing regions (NORs) in carcinomas of the sigmoid colon and rectum. Path Res Pract 1990a; 186:85-91.

Rüschoff J, Plate $\mathrm{KH}$, Contractor $\mathrm{H}$, Kern S, Zimmermann $\mathrm{R}$, Thomas C. Evaluation of nucleolus organizer regions (NORs) by automatic image analysis: a contribution to standardization. J Pathol 1990b;161: 113-8.

Trerè D, Ceccarelli C, Montanaro L, Tosti E, Derenzini M. Nucleolar size and activity are related to $\mathrm{pRb}$ and $\mathrm{p} 53$ status in human breast cancer. J Histochem Cvytochem 2004;52: 1601-7.

Tuccari G, Giménez-Mas JA, Fedele F, Del-Agua C, Melcon B, Trombetta JC, et al. The AgNOR quantity as prognostic parameter in choroidal melanomas: a standardized analysis. Anal Cell Pathol 1999;19: 163-8.

Tuccari G, Giuffrè G, Catalano A, Lentini M, Batolo D. Standardized AgNOR analysis in actinic keratosis. Am J Dermatopathol 2001;23: 407-12. 
G. Giuffrè et al.

60 